\section{OPEN ACCESS \\ Edited by: \\ Giovanni Luca,}

University of Perugia, Italy

Reviewed by:

Alvaro Sanabria,

University of Antioquia, Colombia

Xinying $\mathrm{Li}$,

Central South University, China Justine Philteos,

University of Toronto, Canada

Barbara Maria Jarzab, Maria Skłodowska-Curie National Research Institute of Oncology,

Poland

*Correspondence: Christiaan F. Mooij c.mooij@amsterdamumc.nl

Specialty section:

This article was submitted to

Cancer Endocrinology,

a section of the journal

Frontiers in Endocrinology

Received: 31 May 2021 Accepted: 14 September 2021 Published: 29 September 2021

Citation: van Rooijen JJ, van Trotsenburg ASP, van de Berg DJ, Zwaveling-Soonawala N,

Nieveen van Dijkum EJM, Engelsman AF, Derikx JPM and Mooij CF (2021) Complications After

Thyroidectomy in Children: Lymph Node Dissection Is a Risk Factor for

Permanent Hypocalcemia.

Front. Endocrinol. 12:717769. doi: 10.3389/fendo.2021.717769

\title{
Complications After Thyroidectomy in Children: Lymph Node Dissection Is a Risk Factor for Permanent Hypocalcemia
}

Jesse J. van Rooijen ${ }^{1}$, A. S. Paul van Trotsenburg ${ }^{1}$, Daniël J. van de Berg ${ }^{2}$, Nitash Zwaveling-Soonawala ${ }^{1}$, Els J. M. Nieveen van Dijkum ${ }^{3}$, Anton F. Engelsman ${ }^{3}$, Joep P. M. Derikx ${ }^{2}$ and Christiaan F. Mooij ${ }^{1 *}$

\footnotetext{
1 Department of Pediatric Endocrinology, Emma Children's Hospital, Amsterdam University Medical Centers, University of Amsterdam, Amsterdam, Netherlands, ${ }^{2}$ Department of Pediatric Surgery, Emma Children's Hospital, Amsterdam University Medical Centers, University of Amsterdam and Vrije Universiteit, Amsterdam, Netherlands, ${ }^{3}$ Department of Surgery, Amsterdam University Medical Centers, University of Amsterdam and Vrije Universiteit, Amsterdam, Netherlands
}

Background: Thyroidectomy is a treatment option in some benign thyroid disorders and the definitive treatment option for thyroid cancer. As postoperative mortality is extremely rare data on postoperative complications and long-term health consequences are important.

Objective: To evaluate the frequencies of short- and long-term complications, and their risk factors in pediatric patients (0-18 years) who underwent a thyroidectomy in a tertiary children's hospital.

Methods: A retrospective single center study was performed including all pediatric patients who underwent a thyroidectomy between January 2013 and February 2020.

Results: Forty-eight patients were included in this study (mean age 14.6 years). Twentynine total thyroidectomies and 19 hemithyroidectomies were conducted. Thyroid carcinoma was the indication to perform a thyroidectomy in 12 patients, 36 patients underwent a thyroidectomy because of a benign thyroid disorder. Postoperative hypocalcemia was evaluated in patients who underwent a total thyroidectomy. Rapidly resolved hypocalcemia was observed in three patients (10.3\%), transient hypocalcemia in 10 patients (34.5\%) and permanent hypocalcemia in six patients (20.7\%). Permanent hypocalcemia was only seen in patients who underwent a thyroidectomy combined with additional lymph node dissection because of thyroid carcinoma [thyroid carcinoma: OR 43.73, 95\% Cl (2.11-904.95); lymph node dissection: OR 76.14, 95\% Cl (3.49-458.98)]. Transient and permanent recurrent laryngeal nerve injury was reported in four (8.3\%) and one $(2.1 \%)$ of all patients, respectively.

Conclusion: Permanent postoperative complications after thyroidectomy are rare in pediatric patients undergoing a thyroidectomy without lymph node dissection. However, in this age group permanent hypocalcemia occurs more frequently after thyroidectomy with additional lymph node dissection because of thyroid cancer. With respect to quality of 
life, especially of pediatric thyroid cancer patients, reducing this complication is an important goal.

Keywords: thyroid cancer, Graves' disease, thyroidectomy, hypocalcemia, recurrent laryngeal nerve (RLN) injury, postoperative complications

\section{INTRODUCTION}

Thyroidectomy is the cornerstone of treatment for pediatric thyroid cancer. Furthermore, it is a definitive treatment option for benign thyroid disorders such as Graves' disease and benign thyroid nodules (1-6). Prophylactic thyroidectomy can be considered in patients with an increased risk of developing thyroid cancer to prevent the development of malignant disease later in life $(7,8)$. Mortality after thyroidectomy is very low and the thirty-years survival in pediatric patients with well-differentiated thyroid cancer is $95 \%$ (9). Therefore, data on postoperative complications in children are important as these complications may have a significant impact on quality of life (10-12).

Postoperative hypocalcemia and recurrent laryngeal nerve (RLN) injury are complications specific for thyroid surgery. Both can be transient or permanent problems $(11,12)$. In most cases, postoperative hypocalcemia is caused by hypoparathyroidism due to devascularization or accidental removal of the parathyroid glands $(10,12)$. Permanent hypocalcemia/hypoparathyroidism requires lifelong treatment with calcium and/or active vitamin $\mathrm{D}$ $(13,14)$. Almquist et al. even reported a twofold increased risk of death in adult patients who developed permanent hypocalcemia due to total thyroidectomy (15). Postoperative RLN injury is caused by damage to the nerve and may result in hoarseness and dysphagia $(10,16)$. Other general postoperative complications that can be seen after thyroidectomy include hemorrhage, wound infection and keloid formation (12).

To date several studies reported frequencies of complications after pediatric thyroidectomy $(1,10,11)$. In this study we aimed to additionally identify possible risk factors for the occurrence of postoperative complications for better counseling of pediatric patients and parents.

\section{MATERIALS AND METHODS}

\section{Study Design and Data Collection}

A single center retrospective cohort study was conducted in all pediatric patients (age below 18 years) who underwent a thyroidectomy between January $1^{\text {st }} 2013$ and February $1^{\text {st }} 2020$. All included patients were treated in the Emma Children's Hospital, Amsterdam University Medical Centers, a tertiary care hospital for pediatric endocrine disorders including surgical treatment. All pediatric patients who underwent a thyroidectomy were identified in the pediatric endocrinology new patients' database (started in January 2012). The study was approved by the local Medical Ethical Committee (Amsterdam UMC) (reference number W20_076) and confirmed that the Medical Research Involving Human Subjects act (WMO) does not apply to this study, meaning that formal approval of patients/parents was not needed.
Disease and patient characteristics (age at time of thyroidectomy and gender) were collected for all included patients. The pre- and postoperative diagnosis, preoperative thyroid function parameters and details on the performed surgical procedure (use of intraoperative nerve monitoring, method of vessel ligation technique, number of identified parathyroid glands and parathyroid re-implantation) were collected from the electronic patient charts. For each patient it was evaluated if they were preventively treated with active vitamin $\mathrm{D}$ (calcitriol). To evaluate the presence of postoperative complications, data on postoperative calcium levels, signs of RLN injury, hemorrhage or keloid development were collected. Furthermore, the need and reason of postoperatively started calcium and/or active vitamin $\mathrm{D}$ treatment was registered. The follow-up duration of each patient was identified.

\section{Surgical Procedure}

Thyroid surgery was always performed by a pediatric surgeon with special interest in endocrine surgery and an endocrine surgeon performing more than 50 thyroidectomies per year. Thyroid surgery in this study was defined as hemithyroidectomy or total thyroidectomy. Total thyroidectomy was subclassified as total thyroidectomy only, total thyroidectomy in two tempi (a hemithyroidectomy followed by a completion thyroidectomy removing the contralateral thyroid lobe), and total thyroidectomy (in two tempi) with central and/or lateral neck dissection. The used method of ligating blood vessels was reported as electrocoagulation (use of energy device) (17) or the use of sutures (tie and knot technique). Intraoperative nerve monitoring was used in most thyroidectomies and data on the reported loss of signal of nerve integrity monitor (NIM; NIM-RESPONSE 3.0, Medtronic, MN, USA) during operation was extracted from the electronic patient chart (18). The vast majority of the patients that underwent a total thyroidectomy were treated with active vitamin D (calcitriol) preoperatively to reduce the risk of postoperative hypocalcemia according to our local protocol. When hypocalcemia did not occur or additional interventions were not needed, active vitamin D usage was stopped at the $16^{\text {th }}$ day after surgery.

\section{Postoperative Complications}

The postoperative complications evaluated within this study were transient and permanent hypocalcemia, transient and permanent RLN injury, postoperative hemorrhage and keloid formation. Some patients developed a postoperative drop in calcium levels which resolved within the first 36 hours after surgery, which we scored as "rapid resolved hypocalcemia". Superior laryngeal nerve injury was not monitored due to its variable anatomy and difficulty of detecting it (19). The definitions used for the complications are described in detail in Table 1. 
TABLE 1 | Definitions used for the different postoperative complications evaluated in pediatric patients after thyroidectomy.

\begin{tabular}{|c|c|}
\hline Postoperative complication & Definition \\
\hline \multirow[t]{4}{*}{ Hypocalcemia } & - At least one calcium plasma level $<2.0 \mathrm{mmol} / \mathrm{L}$ with clinical signs of hypocalcemia OR \\
\hline & - At least one total calcium plasma level $<1.9 \mathrm{mmol} / \mathrm{L}$ with or without clinical signs of hypocalcemia AND \\
\hline & - Treatment with calcium in addition to perioperative preparation with active vitamin D OR \\
\hline & - Post operative start of calcium/active vitamin D without preoperative preparation. \\
\hline \multirow[t]{2}{*}{ Rapid resolved hypocalcemia } & - Calcium treatment could be stopped before discharge without prolonged hospitalization OR \\
\hline & - Treatment with calcium could be stopped and perioperative active vitamin D scheme could be continued without changes. \\
\hline \multirow[t]{2}{*}{ Transient hypocalcemia } & - Required prolonged preoperative supplementation with active vitamin D postoperative to normalize calcium levels OR \\
\hline & $\begin{array}{l}\text { - Required supplementation with calcium and/or active vitamin D to achieve normal calcium levels up to six months after } \\
\text { thyroidectomy. }\end{array}$ \\
\hline Permanent hypocalcemia & - Required supplementation with calcium and/or active vitamin D longer than six months post thyroidectomy. \\
\hline \multirow[t]{3}{*}{ Recurrent laryngeal nerve (RLN) injury } & - Postoperative dysphagia and/or hoarseness AND/OR \\
\hline & - Loss of signal of nerve integrity monitor AND \\
\hline & - Need of visiting a speech therapist \\
\hline Transient RLN injury & - Symptoms of RLN neuropraxia resolving within six months \\
\hline Permanent RLN injury & - Symptoms of RLN neuropraxia persisting six months after thyroidectomy \\
\hline Post-operative hemorrhage & - Need of re-operation for hemorrhage. \\
\hline Keloid & - Identification of keloid by the surgeon. \\
\hline
\end{tabular}

Hypocalcemia was only evaluated in those patients who underwent a total thyroidectomy or a completion thyroidectomy due to the predicted very low risk of postoperative hypocalcemia after a hemithyroidectomy. When patients were lost to follow-up within the first six months after thyroidectomy (in most cases because patients were referred to the pediatrician in their local hospital for further follow-up) but were normocalcemic without supplementation or did not have signs of RLN injury during the last visit to our outpatient clinic, they were scored as not having permanent RLN injury or hypocalcemia. None of the patients requiring supplementation because of hypocalcemia were lost to follow up. If patients were lost to follow up within the first six months after thyroidectomy and did not develop signs of keloid at that time, they were excluded for the evaluation of keloid development as keloid can still develop later after surgery (Table 1).

\section{Statistical Analysis}

Descriptive statistics were used to describe complication rates and are presented as medians with range. Normality of distribution of data was assessed with the Kolmogorov-Smirnov test. Odds ratios were calculated using a univariate analysis to identify risk factors for postoperative complications. The presence of complications in patients with benign versus malignant disease, and in patients who underwent a total thyroidectomy only versus total thyroidectomy plus lymph node dissection were compared. A pvalue of $<0.05$ was considered as statistically significant. The Haldane-Anscombe correction was used as a zero-cell correction for calculation of odds ratios (20). SPSS Version 25 (SPSS, Chicago, IL, USA) was used to perform statistical analyses.

\section{RESULTS}

\section{Demographics and Clinical Characteristics}

All 48 pediatric patients who underwent a thyroidectomy between January $1^{\text {st }} 2013$ and February $1^{\text {st }} 2020$ within the
Emma Children's Hospital, Amsterdam University Medical Centers were included (Table 2). The median age at the time of operation was 14.6 years (range: 3.9 - 17.9 years) with a median follow-up duration of 1.6 years (range: $0.1-6.0$ years). The follow-up duration was 12 to 24 months in $27.1 \%$ of the patients $(n=13)$, and longer than 24 months in $37.5 \%$ of the patients $(\mathrm{n}=18)$.

The majority of the patients were female $(n=37 ; 77.1 \%)$ and underwent a thyroidectomy because of a benign condition ( $\mathrm{n}=36 ; 75.0 \%$ ). The patients with a benign thyroid condition were diagnosed with Graves' disease ( $\mathrm{n}=12 ; 25.0 \%)$, benign thyroid nodule(s) ( $\mathrm{n}=16 ; 33.3 \%)$, Hashimoto's disease $(\mathrm{n}=1$; $2.1 \%)$, piriform sinus fistula $(\mathrm{n}=2 ; 4.2 \%)$, goiter due to Pendred syndrome $(n=1 ; 2.1 \%)$, goiter due to a congenital activating TSH receptor mutation $(\mathrm{n}=1 ; 2.1 \%)$ and multiple endocrine neoplasia type $2 \mathrm{~A}$ without thyroid carcinoma (prophylactic thyroidectomy) $(\mathrm{n}=3 ; 6.3 \%)$. Twelve patients $(25.0 \%)$ underwent a thyroidectomy because of malignancy (papillary thyroid carcinoma in all cases).

Preoperative thyroid function parameters were measured in 33 patients. Thirty-one (93.9\%) of them were classified as euthyroid [free T4 levels within the local reference range: $10-23 \mathrm{pmol} / \mathrm{L}$ ] at the time of surgery. Two patients with Graves' disease were hyperthyroid at the time of surgery based on their free T4 levels. One of these patients underwent surgery with a preoperative free T4 level of $29.9 \mathrm{pmol} / \mathrm{L}$. The other patient had a free T4 level of $67.9 \mathrm{pmol} / \mathrm{L}$, but was clinically classified as euthyroid because of normalization of $\mathrm{T} 3$ levels before surgery due to rapid preoperative preparation with high dose propylthiouracil, propranolol, hydrocortisone and amiodarone (21).

\section{Surgical Details}

Forty-eight patients were operated 51 times (Table 2). The thyroidectomies were classified as hemithyroidectomy $(\mathrm{n}=19$; $39.6 \%)$ or total thyroidectomy $(n=29 ; 60.4 \%)$. Two of the total thyroidectomies were performed in two tempi because of the 
TABLE 2 | Demographic, clinical and surgical characteristics of 48 included patients.

\begin{tabular}{lc}
\hline Variable & Number (\%) \\
\hline Demographics & \\
Age at time of surgery (median [range], years) & $14.6[3.9-17.9]$ \\
Female & $37(77.1)$ \\
Male & $11(22.9)$ \\
Indications for surgery & \\
Graves' disease & $12(25.0)$ \\
Other benign & $24(50.0)$ \\
Thyroid carcinoma & $12(25.0)$ \\
Type of surgery & \\
Hemithyroidectomy & $19(39.6)$ \\
Total thyroidectomy & $29(60.4)$ \\
Total thyroidectomy only & $18(37.5)$ \\
Total thyroidectomy in two tempi only & $2(4.2)$ \\
Total thyroidectomy in two tempi with central neck & $1(2.1)$ \\
dissection & \\
Total thyroidectomy plus central neck dissection & $3(6.3)$ \\
Total thyroidectomy plus central and lateral neck dissection & $5(10.4)$ \\
Pre-operative levels of TSH and free T4 & \\
TSH (median [range], mU/L) & $0.4[0.0-4.4]^{\mathrm{a}}$ \\
Free T4 (median [range], pmol/L) & $14.3[8.1-67.9]^{\mathrm{a}}$ \\
Patients who received perioperative active vitamin D & $25(86.2)^{\mathrm{b}}$ \\
supplementation & \\
\hline &
\end{tabular}

${ }^{a}$ Perioperative TSH and Free T4 levels were measured in 33 patients.

${ }^{b}$ Since our local guideline only recommends perioperative active vitamin $D$ for a total thyroidectomy, our frequency is based on total thyroidectomies $(n=29)$.

histopathological diagnosis thyroid cancer. In nine of the twelve patients diagnosed with thyroid carcinoma additional lymph node dissection was performed according to the current guidelines (22). In one patient with thyroid cancer a hemithyroidectomy was performed; due to comorbidity and the small size of the T1 tumor follow-up by ultrasonography was preferred over a completion thyroidectomy. Postoperative mortality was not seen in the studied cohort.

In the vast majority of thyroidectomies vessel ligation was performed by electrocoagulation (LigaSure, $\mathrm{n}=41 ; 85.4 \%$ ). In five thyroidectomies (10.4\%) vessel ligation was performed using the tie-and-knot technique. In two (4.2\%) thyroidectomies the used vessel ligation method was not specified within the surgery record.
NIM was used in 47 out of 48 thyroidectomies (97.9\%) to monitor RLN integrity. In most thyroidectomies (75.0\%) no loss of signal was perceived by the end of surgery. In seven thyroidectomies $(14.6 \%)$ a unilateral loss of signal occurred. In four $(8.3 \%)$ of the thyroidectomies the quality of NIM signal was not described in the surgical record.

Pathology reports of all patients who underwent a total or completion thyroidectomy were evaluated. In 17 (58.6\%) of all 29 pathology reports the number of found parathyroid glands was clarified. In four (13.8\%) pathology reports it was reported that parathyroid tissue was not present in the specimen. In seven (24.1\%) specimens one parathyroid gland was found, in five (17.2\%) specimens two parathyroid glands were found, and in one specimen four parathyroid glands were found (3.4\%). In the remaining $12(41.4 \%)$ pathology reports the number of identified parathyroid glands was not specified, probably because in those cases no parathyroid glands were removed. Auto-transplantation of parathyroid glands was carried out in five of 29 total thyroidectomies, in two of these cases parathyroid tissue was not present in the pathology specimen.

\section{Postoperative Complications}

The frequencies of postoperative complications are reported in Tables 3A, B. Preoperative calcium levels were normal in all patients who underwent a total or completion thyroidectomy. Postoperative calcium levels were only evaluated in the patients who underwent a total or completion thyroidectomy $(n=29$; Table 3A). Postoperative hypocalcemia (rapid resolved, transient or permanent) occurred in a total of 19 patients $(65.5 \%)$. Rapid resolved hypocalcemia was reported in three patients (10.3\%), who did not need treatment, and were all discharged from the hospital three days after surgery with normal calcium levels. Transient hypocalcemia was reported in ten patients $(34.5 \%)$ of which three patients underwent autotransplantation of a parathyroid gland during thyroidectomy. Permanent hypocalcemia was present in six patients $(20.7 \%)$, and all these six patients had undergone lymph node dissection because of metastatic thyroid cancer $(54.5 \%$ of all patients with thyroid cancer; $66.7 \%$ of all patients who underwent additional

TABLE 3A | Postoperative hypocalcemia in pediatric patients who underwent a total thyroidectomy.

\begin{tabular}{|c|c|c|c|}
\hline & $\begin{array}{l}\text { Rapid resolved } \\
\text { hypocalcemia (n) }\end{array}$ & $\begin{array}{c}\text { Transient } \\
\text { hypocalcemia (n) }\end{array}$ & $\begin{array}{c}\text { Permanent } \\
\text { hypocalcemia }(n)\end{array}$ \\
\hline \multicolumn{4}{|l|}{ All patients $(n=29)^{a}$} \\
\hline & 3 & 10 & 6 \\
\hline \multicolumn{4}{|l|}{ Total thyroidectomy only $(n=20)$} \\
\hline & 3 & 7 & 0 \\
\hline \multicolumn{4}{|l|}{ Graves' disease $(n=12)$} \\
\hline & 3 & 4 & 0 \\
\hline \multicolumn{4}{|l|}{ Other benign $(n=6)$} \\
\hline & 0 & 3 & 0 \\
\hline \multicolumn{4}{|l|}{ Thyroid carcinoma $(n=2)$} \\
\hline & 0 & 0 & 0 \\
\hline \multicolumn{4}{|l|}{ Total thyroidectomy plus lymph node dissection in metastatic thyroid carcinoma $(n=9)$} \\
\hline & 0 & 3 & 6 \\
\hline
\end{tabular}

${ }^{a}$ This is a subgroup of all patients included in the study $(n=48)$ in whom postoperative calcium levels were measured. 
TABLE 3B | Postoperative complications in pediatric patients who underwent a thyroidectomy.

\begin{tabular}{|c|c|c|c|c|}
\hline & $\begin{array}{l}\text { Transient RLN } \\
\text { (n) }\end{array}$ & $\begin{array}{l}\text { Permanent RLN } \\
\text { (n) }\end{array}$ & $\begin{array}{l}\text { Postoperative } \\
\text { hemorrhage (n) }\end{array}$ & $\begin{array}{l}\text { Keloid }^{b} \\
\text { (n) }\end{array}$ \\
\hline All patients $(n=48)$ & 4 & 1 & 0 & 8 \\
\hline Total thyroidectomy only $(n=20)$ & 1 & 0 & 0 & 3 \\
\hline Graves' disease $(n=12)$ & 1 & 0 & 0 & $2^{c}$ \\
\hline Other benign $(n=6)$ & 0 & 0 & 0 & 1 \\
\hline Thyroid carcinoma $(n=2)$ & 0 & 0 & 0 & 0 \\
\hline $\begin{array}{l}\text { Total thyroidectomy plus lymph node dissection in metastatic thyroid } \\
\text { carcinoma }(n=9)\end{array}$ & 1 & 0 & 0 & 2 \\
\hline Hemithyroidectomy because of benign thyroid disorder $(n=18)$ & 2 & 1 & 0 & $3^{d}$ \\
\hline Hemithyroidectomy because of thyroid carcinoma ${ }^{a}(n=1)$ & 0 & 0 & 0 & 0 \\
\hline
\end{tabular}

a. In one patient with thyroid carcinoma a hemithyroidectomy was performed and therefore no postoperative calcium levels were measured.

b. Six patients had to be excluded due to follow-up period < six months.

c. Four patients had to be excluded due to follow-up period < six months.

d. Two patients had to be excluded due to follow-up period < six month.

lymph node dissection). One of these six patients underwent an auto-transplantation of one parathyroid gland. Due to the low number of patients who did not receive preoperative active vitamin $\mathrm{D}$, we did not evaluate the effect of perioperative active vitamin $\mathrm{D}$ treatment on the frequency of postoperative hypocalcemia. Transient hypocalcemia was seen in patients who underwent a total thyroidectomy because of papillary thyroid carcinoma ( $\mathrm{n}=3$; all three patients underwent a lymph node dissection), Graves' disease $(n=4)$, goiter due to a congenital activating TSH receptor mutation $(\mathrm{n}=1)$, goiter due to Pendred syndrome $(n=1)$ and a prophylactic thyroidectomy $(n=1)$.

RLN injury was observed in five of 48 patients (10.4\%). In the majority of these cases the RLN injury was transient $(80 \% ; n=4)$. Transient RLN injury was seen in patients who underwent a thyroidectomy because of Graves' disease $(n=1)$, a benign thyroid nodule $(n=2)$ or papillary thyroid cancer $(n=1)$. In three of these four patients, symptoms disappeared within three months after surgery, in one patient symptoms resolved five months postsurgery. Permanent RLN injury was seen in only one patient who underwent a hemithyroidectomy because of a benign thyroid nodule $(2.1 \%)$, in this patient a loss of NIM signal was reported during surgery. NIM signal was adequate during thyroidectomy in all patients without signs of RLN injury. Keloid was present in eight patients (19.0\%), none of these patients underwent a thyroidectomy in two tempi. No cases of postoperative hemorrhage were seen. One patient had to undergo a reoperation due to an abscess.

\section{Risk Factors for Postoperative Complication}

Permanent hypocalcemia only occurred in patients who underwent a thyroidectomy because of a malignancy (Table 3A). When comparing patients who underwent a thyroidectomy with patients who underwent a thyroidectomy plus lymph node dissection, the lymph node dissection was associated with permanent postoperative hypocalcemia [OR 76.14, 95\%CI (3.49458.98), ( $\mathrm{p}<0.05)]$. Patients who underwent a thyroidectomy because of thyroid cancer seemed to have a higher risk of permanent postoperative hypocalcemia compared to patients with a benign thyroid disorder [OR 43.73, 95\%CI (2.11-904.95), $(\mathrm{p}<0.05)]$, although this increased risk seems to be attributed to the performance of the additional lymph node dissection in patients with metastatic thyroid cancer.

No other risk factors for transient or permanent complications were identified as all other calculated ORs were not statistically significant (data not shown). However, rapid resolved hypocalcemia tended to be more frequent in patients with Graves' disease (three out of twelve patients) versus other benign thyroid disorders (zero out of six patients).

\section{DISCUSSION}

Mortality after pediatric thyroidectomy is very rare, but complications of thyroidectomy do occur $[6,9,10,11]$. In this study the frequencies of short- and long-term complications in pediatric patients (0-18 year) who underwent a thyroidectomy were evaluated and risk factors associated with postoperative complications were identified. Transient postoperative complications were observed relatively frequent in this study. Permanent RLN injury was extremely rare and only seen in one patient $(2.1 \%)$. Permanent hypocalcemia was not seen in pediatric patients who underwent a thyroidectomy because of a benign thyroid condition, neither in patients who underwent a thyroidectomy without additional lymph node dissection because of thyroid cancer. Overall, permanent hypocalcemia was regularly seen after total thyroidectomy because of thyroid cancer and only in those patients who underwent a central or lateral neck dissection because of metastatic disease. The performance of an additional central or lateral neck dissection (because of thyroid cancer) was associated with an increased risk of postoperative permanent hypocalcemia.

In 2015, we reported quality of life and clinical outcomes after pediatric thyroidectomy carried out between 2000 and 2012 $(n=40)(10)$. In that study period a $10 \%$ frequency of transient RLN paralysis and a $32.5 \%$ frequency of transient hypocalcemia was reported. No cases of permanent RLN injury were reported, while $12.5 \%$ of the studied patients suffered from permanent hypocalcemia (both patients with thyroid cancer or a benign thyroid disorder). These frequencies are in line with those found 
in this study showing a consistent outcome of thyroidectomy in our center over the time.

Postoperative hypocalcemia was the most frequently reported postoperative complication in our cohort of pediatric patients after a total thyroidectomy. The reported frequency of transient hypocalcemia in our cohort $(34.5 \%)$ is in the range of previously reported frequencies of transient hypocalcemia in pediatric patients after thyroidectomy $(5.7 \%-49.3 \%)(1,10,11,23-25)$. The relatively high rate of transient hypocalcemia and thus temporary calcium supplementation in this study may be explained by individual institutional protocols and policies. This may have resulted in an unnecessary start of treatment with calcium/active vitamin D. Furthermore, in our experience some patients experience a very short drop in postoperative calcium levels without causing prolonged hospitalization or longer duration of treatment with calcium or active vitamin D. Therefore, we classified these patients as having 'rapid resolved hypocalcemia'. The occurrence of rapid resolved hypocalcemia was $10.3 \%$ ( $n=3$ out of 29 patients) and is of small clinical relevance. Uniformity in diagnosing and treating postoperative hypocalcemia is needed.

Permanent hypocalcemia occurred in $20.7 \%$ of patients in this study which fits within the previously reported frequencies in other studies $(0.6 \%-21.7 \%)(1,10,11,23-25)$. In adults the incidence is lower compared to children (1.0\% - 12.5\%) (26-28). In our cohort permanent hypocalcemia only occurred in patients who underwent a total thyroidectomy plus lymph node dissection because of thyroid cancer. The results suggest that the additional lymph node dissection, if indicated, in pediatric thyroid cancer patients may be the main cause of permanent hypoparathyroidism as no cases of permanent hypocalcemia are seen after total thyroidectomy without additional lymph node dissection. It has been shown previously in adults that central neck lymph node dissection is an independent risk factor for permanent hypoparathyroidism (29-31). The increased risk of postoperative permanent hypocalcemia in patients who underwent additional lymph node dissection is possibly caused by devascularization or unintentional resection of parathyroid glands (24). However, data on identification and/or reimplementation of parathyroid glands can give more information on the risk of development of postoperative hypocalcemia. De Jong et al. found a higher incidence of postoperative hypocalcemia when a lower number of parathyroid glands remained in situ (11). Due to the retrospective character of this study and the fact that data on the number of identified parathyroid glands during surgery were not fully reported in the medical charts, we could not prove a relation between the number of parathyroid glands that remained in situ and permanent hypocalcemia.

Several factors may reduce the risk of postoperative hypoparathyroidism in the future. First of all, pediatric thyroidectomies should be performed by high-volume dedicated pediatric endocrine surgeons (6), as is the case in our children's hospital. Furthermore, meticulous capsular dissection and the intraoperative localization of the parathyroid glands by fluorescence may reduce the risk of the accidental removal or devascularization of the parathyroid glands $(32,33)$. Intra-operative localization of the parathyroid glands is of great importance during a central neck dissection to prevent damaging the parathyroid glands. As permanent hypocalcemia requires lifelong treatment with active vitamin $\mathrm{D}$ and/or calcium the prevention of this complication would improve the long-term health outcome of especially pediatric patients undergoing a total thyroidectomy.

RLN injury is the second most frequent reported complication after thyroidectomy. The occurrence of transient (8.3\%) and permanent (2.1\%) RLN injury in our study was in line with other studies $(0.6 \%-10 \%$ and $0 \%-1.6 \%$ respectively) $(1,10,23,24)$. The golden standard to detect RLN injury is the use of laryngoscopy revealing vocal cord paralysis (18). Due to the invasive character of laryngoscopy, it is not routinely used in pediatric patient care after thyroidectomy $(1,10,23,24)$. As we believe transient (and permanent) RLN injury is only clinically relevant if symptoms like hoarseness persist after the direct postoperative period, we only classified patients with RLN injury when they were referred to a speech therapist (34). A key aspect in avoiding RLN injury during the operation is identification of the RLN (35). In the majority of thyroidectomies in this study NIM was used, which helps to identify the nerve more easily and guards nerve function to prevent injury (36). Future improvement of techniques identifying the RLN may even further reduce the risk of RLN injury after thyroidectomies in children.

The reported frequency of keloid in our cohort (19\%) was higher compared to previous studies $(0 \%-7 \%)(37,38)$. As this frequency is relatively high, we believe it is important to counsel patients about the risk of keloid development as it may cause pain, itchiness and cosmetic disturbance (39). None of the patients in our cohort developed a postoperative hemorrhage. In most of our patients LigaSure was used as technique for vessel ligation. Since previous studies showed better hemostasis with LigaSure compared to conventional sutures this may explain the absence of postoperative hemorrhage in our cohort (40).

This study has several limitations. Due to the retrospective nature of the study completeness of data differed per patient. In addition, treatment strategies for hypocalcemia were not uniform. In order to specify the occurrence and duration of postoperative hypocalcemia, we used specific criteria (Table 1). The used definitions for most of the complications reported in this study are subjective. This may have influenced the reported frequencies in this study. It has been shown that parathyroid function may recover more than six months after total thyroidectomy (41), as a result the reported frequency of permanent hypocalcemia in our study may have been overestimated. Another important limitation of this study is that postoperative parathyroid hormone (PTH) levels were not measured postoperatively as part of standard care. As data on postoperative PTH levels were lacking we were unable to prove that postoperative hypocalcemia is caused by postoperative hypoparathyroidism. However, the fact that calcium levels were normal preoperatively in all patients indicates that there were no signs of preexisting hypocalcemia. To identify the cause of postoperative hypocalcemia after a total thyroidectomy we suggest incorporating postoperative PTH measurements into the standard biochemical follow-up after a total thyroidectomy. Furthermore, the number of patients included in this study is 
relatively low causing a lack of power for subgroup analysis, a high frequency of complications in certain subgroups and high calculated ORs with wide confidence intervals. The fact that thyroidectomy in children is a rare procedure has led to this relatively low number of included patients. However, the reported cohort from our tertiary referral center is a relatively large cohort compared to previously published studies.

In conclusion, this study showed that permanent complications after thyroidectomy without additional lymph node dissection are rare. However, permanent hypocalcemia is relatively common in pediatric patients with thyroid cancer who require an additional lymph node dissection. Thyroid cancer and especially the performance of a lymph node dissection were associated with an increased risk of permanent hypocalcemia after pediatric thyroidectomy, as already has been shown in adults (27). Further improvement of identification techniques of both the parathyroid glands and RLN are important to reduce risk of postoperative complications and potentially reduce the impact of life long postoperative morbidities on the quality of life, especially in patients with pediatric thyroid cancer.

\section{DATA AVAILABILITY STATEMENT}

The original contributions presented in the study are included in the article. Further inquiries can be directed to the corresponding author.

\section{REFERENCES}

1. Scholz S, Smith JR, Chaignaud B, Shamberger RC, Huang SA. Thyroid Surgery at Children's Hospital Boston: A 35-Year Single-Institution Experience. J Pediatr Surg (2011) 46(3):437-42. doi: 10.1016/j.jpedsurg.2010.09.009

2. Hanley P, Lord K, Bauer AJ. Thyroid Disorders in Children and Adolescents A Review. JAMA Pediatr (2016) 170(10):1008-19. doi: 10.1001/jamapediatrics. 2016.0486

3. Ledbetter DJ. Thyroid Surgery in Children. Semin Pediatr Surg (2014) 23 (2):60-5. doi: 10.1053/j.sempedsurg.2014.03.002

4. Kahaly GJ, Bartalena L, Hegedus L, Leenhardt L, Poppe K, Pearce SH. European Thyroid Association Guideline for the Management of Graves' Hyperthyroidism. Eur Thyroid J (20182018) 7(4):167-86. doi: 10.1159/000490384

5. Breuer C, Tuggle C, Solomon D, Sosa JA. Pediatric Thyroid Disease: When Is Surgery Necessary, and Who Should be Operating on Our Children? J Clin Res Pediatr E (2013) 5:79-85. doi: 10.4274/jcrpe.817

6. Francis GL, Waguespack SG, Bauer AJ, Angelos P, Benvenga S, Cerutti JM, et al. Management Guidelines for Children With Thyroid Nodules and Differentiated Thyroid Cancer. Thyroid (2015) 25(7):716-59. doi: 10.1089/ thy.2014.0460

7. Lodish MB, Stratakis CA. RET Oncogene in MEN2, MEN2B, MTC and Other Forms of Thyroid Cancer. Expert Rev Anticanc (2008) 8(4):625-32. doi: $10.1586 / 14737140.8 .4 .625$

8. Wong KS, Barletta JA. Thyroid Tumors You Don't Want to Miss. Surg Pathol Clin (2019) 12(4):901-19. doi: 10.1016/j.path.2019.08.008

9. Stefan AI, Piciu A, Mester A, Apostu D, Badan M, Badulescu CI. Pediatric Thyroid Cancer in Europe: An Overdiagnosed Condition? A Literature Review. Diagn (Basel) (2020) 10(2):112. doi: 10.3390/diagnostics 10020112

10. Stokhuijzen E, van der Steeg AF, Nieveen van Dijkum EJ, van Santen HM, van Trotsenburg AS. Quality of Life and Clinical Outcome After Thyroid Surgery in Children: A 13 Years Single Center Experience. J Pediatr Surg (2015) 50 (10):1701-6. doi: 10.1016/j.jpedsurg.2015.02.067

11. de Jong M, Nounou H, Garcia VR, Christakis I, Brain C, Abdel-Aziz TE, et al. Children are at a High Risk of Hypocalcaemia and Hypoparathyroidism After

\section{ETHICS STATEMENT}

The studies involving human participants were reviewed and approved by Medical Ethical Committee (Amsterdam UMC). Written informed consent from the participants' legal guardian/ next of kin was not required to participate in this study in accordance with the national legislation and the institutional requirements.

\section{AUTHOR CONTRIBUTIONS}

JvR performed the data collection and analysis under supervision of JD and CM. JvR, JD, and CM took the lead in writing the manuscript. AvT, NZ-S, ENvD, AE, JD, and CM were all involved in the clinical care for the patients included in this study. AvT, DvdB, NZ-S, ENvD, and AE critically reviewed and improved the manuscript. All authors contributed to the article and approved the submitted version.

\section{FUNDING}

This research was financially supported by a Steun Stichting Emma Kinderziekenhuis grant (project number WAR2020-10).

Total Thyroidectomy. J Pediatr Surg (2020) 55(7):1260-4. doi: 10.1016/ j.jpedsurg.2019.06.027

12. Rosato L, Avenia N, Bernante P, De Palma M, Gulino G, Nasi PG, et al. Complications of Thyroid Surgery: Analysis of a Multicentric Study on 14,934 Patients Operated on in Italy Over 5 Years. World J Surg (2004) 28(3):271-6. doi: 10.1007/s00268-003-6903-1

13. Radakrishnan A, Reddy AT, Dalal P, Rastatter JC, Josefson JL, Samis JH, et al. Hypocalcemia Prevention and Management After Thyroidectomy in Children: A Systematic Review. J Pediatr Surg (2021) 56(3):526-33. doi: 10.1016/j.jpedsurg.2020.08.032

14. Cooper MS, Gittoes NJL. Diagnosis and Management of Hypocalcaemia. Brit Med J (2008) 336(7656):1298-302. doi: 10.1136/bmj.39582.589433.BE

15. Almquist M, Ivarsson K, Nordenstrom E, Bergenfelz A. Mortality in Patients With Permanent Hypoparathyroidism After Total Thyroidectomy. Brit J Surg (2018) 105(10):1313-8. doi: 10.1002/bjs.10843

16. Joliat GR, Guarnero V, Demartines N, Schweizer V, Matter M. Recurrent Laryngeal Nerve Injury After Thyroid and Parathyroid Surgery Incidence and Postoperative Evolution Assessment. Medicine (2017) 96(17):e6674. doi: 10.1097/MD.0000000000006674

17. O'Neill CJ, Chang LY, Suliburk JW, Sidhu SB, Delbridge LW, Sywak MS. Sutureless Thyroidectomy: Surgical Technique. Anz J Surg (2011) 81(78):515-8. doi: 10.1111/j.1445-2197.2010.05493.x

18. Randolph GW, Dralle H, Abdullah H, Barczynski M, Bellantone R, Brauckhoff M, et al. Electrophysiologic Recurrent Laryngeal Nerve Monitoring During Thyroid and Parathyroid Surgery: International Standards Guideline Statement. Laryngoscope (2011) 121:S1-S16. doi: 10.1002/lary.21119

19. Cheruiyot I, Kipkorir V, Henry BM, Munguti J, Cirocchi R, Odula P, et al. Surgical Anatomy of the External Branch of the Superior Laryngeal Nerve: A Systematic Review and Meta-Analysis. Langenbeck Arch Surg (2018) 403 (7):811-23. doi: 10.1007/s00423-018-1723-9

20. Agresti A. On Logit Confidence Intervals for the Odds Ratio With Small Samples. Biometrics (1999) 55(2):597-602. doi: 10.1111/j.0006-341X.1999.00597.x

21. Mooij CF, Zwaveling-Soonawala N, Fliers E, van Trotsenburg ASP. The Use of the Iodine-Rich Drug Amiodarone in the Rapid Preoperative Preparation for 
Thyroidectomy Because of Persistent Hyperthyroidism. Eur Thyroid J (2019) 8(3):167-8. doi: 10.1159/000499104

22. Lebbink CA, Dekker BL, Bocca G, Braat AJAT, Derikx JPM, Dierselhuis MP, et al. New National Recommendations for the Treatment of Pediatric Differentiated Thyroid Carcinoma in the Netherlands. Eur J Endocrinol (2020) 183(4):P11-P8. doi: 10.1530/EJE-20-0191

23. Sinha CK, Decoppi P, Pierro A, Brain C, Hindmarsh P, Butler G, et al. Thyroid Surgery in Children: Clinical Outcomes. Eur J Pediatr Surg (2015) 25(5):425-9. doi: 10.1055/s-0034-1384649

24. Baumgarten HD, Bauer AJ, Isaza A, Mostoufi-Moab S, Kazahaya K, Adzick NS. Surgical Management of Pediatric Thyroid Disease: Complication Rates After Thyroidectomy at the Children's Hospital of Philadelphia High-Volume Pediatric Thyroid Center. J Pediatr Surg (2019) 54(10):1969-75. doi: 10.1016/ j.jpedsurg.2019.02.009

25. Nordenstrom E, Bergenfelz A, Almquist M. Permanent Hypoparathyroidism After Total Thyroidectomy in Children: Results From a National Registry. World J Surg (2018) 42(9):2858-63. doi: 10.1007/s00268-018-4552-7

26. Edafe O, Antakia R, Laskar N, Uttley L, Balasubramanian SP. Systematic Review and Meta-Analysis of Predictors of Post-Thyroidectomy Hypocalcaemia. Br J Surg (2014) 101(4):307-20. doi: 10.1002/bjs.9384

27. Bergenfelz A, Nordenstrom E, Almquist M. Morbidity in Patients With Permanent Hypoparathyroidism After Total Thyroidectomy. Surgery (2020) 167(1):124-8. doi: 10.1016/j.surg.2019.06.056

28. Anneback M, Hedberg J, Almquist M, Stalberg P, Norlen O. Risk of Permanent Hypoparathyroidism After Total Thyroidectomy for Benign Disease: A Nationwide Population-Based Cohort Study From Sweden. Ann Surg (2020). doi: 10.1097/SLA.0000000000003800

29. Zhou HY, He JC, McHenry CR. Inadvertent Parathyroidectomy: Incidence, Risk Factors, and Outcomes. J Surg Res (2016) 205(1):70-5. doi: 10.1016/ j.jss.2016.06.019

30. Giordano D, Valcavi R, Thompson GB, Pedroni C, Renna L, Gradoni P, et al. Complications of Central Neck Dissection in Patients With Papillary Thyroid Carcinoma: Results of a Study on 1087 Patients and Review of the Literature. Thyroid (2012) 22(9):911-7. doi: 10.1089/thy.2012.0011

31. de Leon-Ballesteros GP, Velazquez-Fernandez D, Hernandez-Calderon FJ, Bonilla-Ramirez C, Perez-Soto RH, Pantoja JP, et al. Hypoparathyroidism After Total Thyroidectomy: Importance of the Intraoperative Management of the Parathyroid Glands. World J Surg (2019) 43(7):1728-36. doi: 10.1007/ s00268-019-04987-z

32. Dzodic R, Santrac N. In Situ Preservation of Parathyroid Glands: Advanced Surgical Tips for Prevention of Permanent Hypoparathyroidism in Thyroid Surgery. J BUON (2017) 22(4):853-5.

33. Fortuny JV, Sadowski SM, Belfontali V, Guigard S, Poncet A, Ris F, et al. Randomized Clinical Trial of Intraoperative Parathyroid Gland Angiography With Indocyanine Green Fluorescence Predicting Parathyroid Function After Thyroid Surgery. Brit J Surg (2018) 105(4):350-7. doi: 10.1002/bjs.10783
34. Zaat AS, Derikx JPM, Zwaveling-Soonawala N, van Trotsenburg ASP, Mooij CF. Thyroidectomy in Pediatric Patients With Graves' Disease: A Systematic Review of Postoperative Morbidity. Eur Thyroid J (2021) 10(1):39-51. doi: $10.1159 / 000511345$

35. Tredici P, Grosso E, Gibelli B, Massaro MA, Arrigoni C, Tradati N. Identification of Patients at High Risk for Hypocalcemia After Total Thyroidectomy. Acta Otorhinol (2011) 31(3):144-8.

36. Rulli F, Ambrogi V, Dionigi G, Amirhassankhani S, Mineo TC, Ottaviani F, et al. Meta-Analysis of Recurrent Laryngeal Nerve Injury in Thyroid Surgery With or Without Intraoperative Nerve Monitoring. Acta Otorhinol (2014) 34(4):223-9.

37. Peroni E, Angiolini MR, Vigone MC, Mari G, Chiumello G, Beretta E, et al. Surgical Management of Pediatric Graves' Disease: An Effective Definitive Treatment. Pediatr Surg Int (2012) 28(6):609-14. doi: 10.1007/s00383-012-3095-5

38. Bergman P, Auldist A, Cameron F. Review of the Outcome of Management of Graves' Disease in Children and Adolescents. J Paediatr Child H (2001) 37 (2):176-82. doi: 10.1046/j.1440-1754.2001.00641.x

39. Bijlard E, Kouwenberg CAE, Timman R, Hovius SER, Busschbach JJV, Mureau MAM. Burden of Keloid Disease: A Cross-Sectional Health-Related Quality of Life Assessment. Acta Derm-Venereol (2017) 97(2):225-9. doi: 10.2340/00015555-2498

40. Yao HS, Wang Q, Wang WJ, Ruan CP. Prospective Clinical Trials of Thyroidectomy With LigaSure vs Conventional Vessel Ligation A Systematic Review and Meta-Analysis. Arch Surg-Chicago (2009) 144 (12):1167-74. doi: 10.1001/archsurg.2009.201

41. de Jong MC, Lorente-Poch L, Sancho-Insenser J, Garcia VR, Brain C, AbdelAziz TE, et al. Late Recovery of Parathyroid Function After Total Thyroidectomy in Children and Adults: Is There a Difference? Horm Res Paediat (2021) 93(9-10):539-47. doi: 10.1159/000513768

Conflict of Interest: The authors declare that the research was conducted in the absence of any commercial or financial relationships that could be construed as a potential conflict of interest.

Publisher's Note: All claims expressed in this article are solely those of the authors and do not necessarily represent those of their affiliated organizations, or those of the publisher, the editors and the reviewers. Any product that may be evaluated in this article, or claim that may be made by its manufacturer, is not guaranteed or endorsed by the publisher.

Copyright (c) 2021 van Rooijen, van Trotsenburg, van de Berg, Zwaveling-Soonawala, Nieveen van Dijkum, Engelsman, Derikx and Mooij. This is an open-access article distributed under the terms of the Creative Commons Attribution License (CC BY). The use, distribution or reproduction in other forums is permitted, provided the original author(s) and the copyright owner(s) are credited and that the original publication in this journal is cited, in accordance with accepted academic practice. No use, distribution or reproduction is permitted which does not comply with these terms. 